\title{
Betulin and betulinic acid in cancer research
}

\author{
Anna Hordyjewska', Aleksandra Ostapiuk', Anna Horecka' \\ ${ }^{1}$ Chair and Department of Medical Chemistry, Medical University, Lublin, Poland \\ Hordyjewska A, Ostapiuk A, Horecka A. Betulin and betulinic acid in cancer research. J Pre-Clin Clin Res. 2018; 12(2): 72-75. doi: 10.26444/jpccr/92743
}

\section{Abstract}

Introduction. Terpenes are the largest known class of organic compounds, widely distributed in plants. They are grouped considering the number of isoprene units in their structure; hence, the group consisting of 30 carbon atoms is called triterpenes. These compounds have a wide range of biological features.

Objective. The aim of this review was to comprehensively discuss the role of betulin and betulinic acid as potent anticancer agents, including various studies determining their efficiency in cancer treatment and enumerating the types of cancer susceptible to this kind of therapy.

State of knowledge. Betulin is a naturally occurring lupane-type pentacyclic triterpene, wildly distributed in plants, especially Betulinaceae. One of its derivatives, formed by oxidation, is betulinic acid. Both compounds are abundantly present in the outer bark of white birch, with betulin forming up to $34 \%$ its dry mass and are known for their valuable biological properties, including anti-cancer effect. By inducing the internal apoptosis pathway in cancer cells while sparing normal cells, they are a great help in the treatment of most malignancies, alone or in combination with radio- or chemotherapy.

Summary. Compounds that have a direct effect on mitochondria are promising experimental anticancer drugs, since they are able to cause cell death in conditions in which conventional therapies, including chemotherapeutics, usually fail. Therefore, mitochondrial targeting agents such as betulin and betulinic acid are a promise of a new therapeutic strategy for the treatment of human tumours.

\section{Key words}

terpenoids, triterpenoids, lupanoles, betulin, betulinic acid, cancer

\section{INTRODUCTION}

Terpenes, also known as terpenoids or isoprenoids, are the largest class of organic compounds widely distributed in plants. Due to their diversity and ubiquitousness, they serve a variety of important physiological roles [1]. Terpenoids are grouped in accordance with the number of isoprene units in the molecule (Fig. 1). Therefore, classification includes: monoterpenes (C10), sesquiterpenes (C15), diterpenes (C20), sesterterpenes (C25), triterpenes (C30), tetraterpenes (C40) and polyterpenes $[2,3]$.

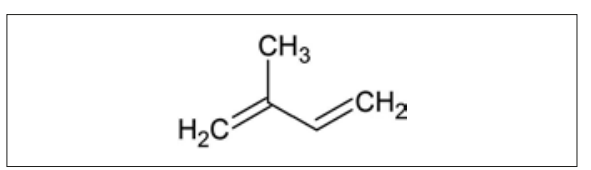

Figure 1. Chemical structure of an isoprene unit

One of the subclasses of terpenes are triterepenoids, a group composed of miscellaneous metabolites of isopentenyl pyrophosphate oligomers. On account of the immense range of their basic backbone modifications, more than 20,000 members of the triterpenoid group have been confirmed to occur in nature. Therefore, triterpenoids form approximately $50 \%$ of the total known amount of terpenes [2, 4]. The vast majority are present in plants, e.g. seaweeds, or in the vax-like substance protecting organs of numerous fruits or herbs, i.a. apples, thyme, lavender or mistletoe [5].

For a long time, 30-carbon terpenoids derivatives were mistakenly considered to be biologically inactive. Although several studies conducted in past years have suggested

Address for correspondence: Anna Hordyjewska, Chair and Department of Medical Chemistry, Medical University, Lublin Chodźki Street 4a, 20-093 Lublin, Poland E-mail: anna.hordyjewska@umlub.pl

Received: 29 May 2018; Accepted: 2 July 2018 that triterpenoids possess various activities, including hepatoprotective, cytotoxic, anti-inflammatory as well as anti-cancer $[6,7]$. This resulted in a constantly growing eagerness to elucidate their potential.

Biosynthesis of triterpenoids occurs through cyclization of squalene, a 30-carbon intermediate, precursor of all steroids [8]. As a result of the process, numerous groups are formed, including protostanes, cycloartanes, holostanes, cucurbitanes, euphanes, tetranortriterpenoids, lupanes, oleananes, ursanes and saponins, and a wide range of other compounds [9].

\section{OBJECTIVE}

The aim of this brief review was to present the role of lupanetype triterpenoid, betulin, and its oxidation product, betulinic acid, as potent anti-cancer agents. Particular attention has been drawn to numerous studies determining the efficacy of betulin and betulin in both in vitro and in vivo cancer treatment and their impact on non-malignant cells. Research on molecular scheme of tumour cytotoxicity of the abovementioned substances is also discussed. Potential types of cancer in which the use of these lupane derivatives in research yielded tangible results are additionally mentioned.

\section{STATE OF KNOWLEDGE}

Triterpenes of lupanes, oleananes and ursanes can be found in various plant organs, including cork, bark or in the abovementioned vax coating of leaves. In the majority of species, pentacyclic triterpenes cover less than $0.1 \%$ of the dry weight of plant organs. However, several exceptions displaying an amount higher than $1 \%$, have been noted [10]. 
Chemical structure and natural occurrence of betulin and betulinic acid. The highest percentage of triterpenes in dry mass has been found in the outer bark of white birch, which contains up to $34 \%$ of pentacyclic triterpenoid called betulin [10]. Betulin, lup-20(29)-ene-33,28-diol, also referred to as betulinol or betulinic alcohol, is a compound formed from the lupane skeleton, as evidenced by the presence of an isopropylidene group and five-membered ring [11] (Fig. 2A). It was one of the first natural chemical substances isolated from plants, with its isolation dated to 1788. Betulin is widespread in the Betulaceae family, e.g. in Betula alba or Betula pendula [12]. Besides the accessibility of betulin in dry weight, it is possible to efficiently obtain it by extraction. Since betulin can account for more than $50 \%$ of the extract, this process appears to be a feasible and efficient source of this material [13].

Unfortunately, the chemical structure of betulin limits its solubility in aqueous media. However, the undeniable advantage of the mentioned triterpenoid is that it can be used as a starting compound for other more soluble substances. With its broad spectrum of properties, derivatives are often found to be useful in the development of science and medicine. One of such congeners is betulinic acid, $3 \beta$-hydroxylup-20(29)-en-28-oic acid, a product of betulin oxidation, also detected in white birch bark [14] (Fig. 2B).

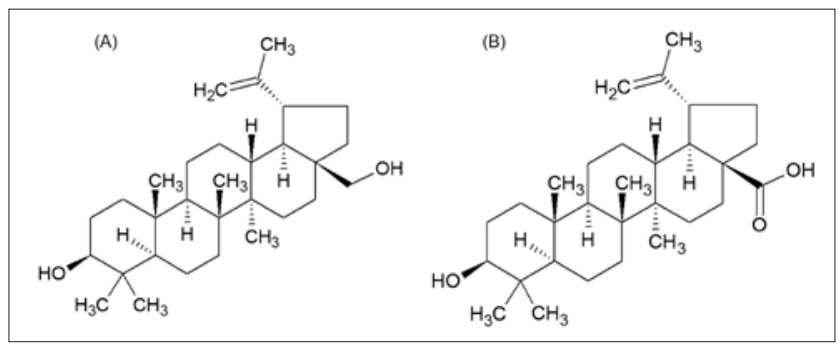

Figure 2. Structures of $(\mathbf{A})$ betulin and $(\mathbf{B})$ betulinic acid

\section{THERAPEUTIC PROPERTIES OF BETULIN AND BETULINIC ACID}

Wide range of betulin and betulinic acid properties. Natural resources have been used for centuries as an aid in combating various diseases. nturies. One of the most helpful remedies of natural origin was white birch bark, used in the folk medicine of Asians and Native Americans. Beverages or compresses from the bark of Betulaceae, rich in betulin and betulinic acid, have been exploited to treat intestinal problems [15]. Despite the passage of time, naturally-derived substances still play an important role in discovering new drugs and the development of pharmacology [16].

In recent times, numerous studies have been conducted to reveal many valuable properties of both betulin and betulinic acid: i.a. antiviral (anti-influenza, anti-HIV), antiinflammatory, antiallergenic, antihypoxic, liver protectant, and antituberculosis [11]. The most important property, however, turned out to be its comprehensive anti-cancer effect.

Anticancer activity of betulinic acid. Despite the ongoing improvement of modern anti-cancer therapies, high mortality rates and toxic side effects are still an unsolved problem in cancer treatment. Thus, researchers found it inevitable to develop some kind of powerful anti-tumour agent with lesser or none toxicity.

The first present-day information describing prospective anti-cancer effects of the compound found in white birch bark date back to 1995, when Emily Pisha et al. at the University of Illinois described betulinic acid as a potential selective inhibitor of human melanoma cells. Research consisting of in vitro and in vivo studies have proved that this betulin derivative killed melanoma cells in mice [17]. Considering that, invariably from the 1990s attention has been focused on betulin and betulinic acid with their unusual properties.

Thereafter, numerous scientists conducted studies aimed at providing an insight into the anticancer properties of betulinic acid. From this date onwards, the antitumour cytotoxicity of the compound has been wildly studied in vitro - in tumour samples, as well as in vivo - in cancer cell lines or mouse models subjected to xenograft transplants.

One feature of betulinic acid that drew the greatest attention of the scientific world during the research, was its potent ability to mediate the molecular mechanisms of cytotoxicity. Namely, betulinic acid is a specific inducer of the mitochondrial pathway of apoptosis in tumours [18].

Despite the fact that initially betulinic acid was tested for anti-cancer effect on cell lines of melanoma, its cytotoxic activity was expanded shortly afterwards to the panel of other human cancer types, including paediatric cancers: neuroblastoma, medulloblastoma, Ewing sarcoma; haematological malignancies, including multiple myeloma, lymphoma, as well as glioblastoma, breast, head and neck, colon, gastric, hepatocellular, cervix, lung, pancreatic, renal cell, ovarian, or prostate carcinoma [14, 19-27].

Furthermore, betulinic acid was observed to show cytotoxicity on samples of primary childhood acute leukaemia that was refractory to conventional forms of chemotherapy [28]. Another interesting result evidenced that in melanoma samples, betulinic acid acts selectively cytotoxic against metastatic cell lines, as opposed to those non-malignant [27]. Some studies also suggest that betulinic acid can be used as an effective enhancer in cancer therapies, according to the fact that it was tested as a suppressor of malignant cell growth.

Comparison of cytotoxicity of betulin and betulinic acid directed to tumour cells. On the basis of published reports, it was revealed that not only betulinic acid but also betulin can also act as a tumour cytotoxicity inducer, i.a. in lung, gastric or pancreatic cancer treatment. In general, both tested compounds revealed significant cytotoxicity, although it was betulinic acid that was reported to be more effective [29]. However, there is a difference worth mentioning, noticed by Rzeski et al. In their study, betulin appeared to be more cytotoxic than its derivative considering cells derived from nervous system carcinomas (glioma, neuroblastoma). Moreover, for reasons unknown to researchers, all primary tumour cells, especially ovarian carcinomas, showed greater sensitivity to betulin than betulinic acid in treatment [30].

Fortunately, while betulin itself may not be such a potent cytotoxic agent as its oxidation product, several studies demonstrate that even minor change in the main structure of this triterpene may be sufficient to obtain biologically and therapeutically important derivatives [11].

Moreover, both betulin and betulinic acid can be successfully combined with miscellaneous cytotoxic forms of 
treatment, including ionizing radiation or chemotherapeutic agents, such as vincristine, doxorubicin, etoposide, cisplatin etc. [31-33]. Results have shown that cancer cells were characterised by much lower resistance to betulin and its derivative compared to normal cells, regardless of origin. The outcomes clearly indicate the selectivity of these compounds in tumour cytotoxicity $[19,34]$.

Betulinic acid as an anti-cancer agent in mice models. Apart from its extraordinary anticancer cytotoxicity potential in cell cultures, betulinic acid has also been reported to be a cancer growth suppressor in xenograft mouse models. The very first study testing its potential anti-tumour activity confirmed that betulinic acid halts the growth of melanoma, both in vitro and in mice [17]. Subsequently, while studying the influence of betulinic acid on ovarian carcinoma xenografts, scientists learned that the survival time of mice treated with betulinic acid was significantly extended compared to control [34]. Of note, a different study also revealed a decreased number of lung metastases in animals with highly malignant and metastatic breast tumours treated with betulinic acid [35].

Remarkably, in all the above-mentioned studies, no significant weight loss or symptoms of systemic toxicity were present, regardless of doses. Moreover, another mouse models experiment conducted to study the pharmacokinetics of betulinic acid, reported that it was well absorbed and distributed with the highest concentrations in the tumour [36]. Over time, it was revealed that the lack of cytotoxicity applies not only to betulinic acid, but also to betulin itself [37].

Combined therapy of betulin or betulinic acid and chemotherapeutics. Besides its in vivo activity as a single cytotoxic agent, betulinic acid has also been proved to be able to successfully cooperate with numerous chemotherapeutics, including the already mentioned vincristine [32]. Researchers fused anti-tumour activities of these agents while analysing an in vivo model of malignant metastatic melanoma. The results showed significantly induced lung metastasis suppression in mice with melanoma cells treated by vincristine and betulinic acid combined. Simultaneously, the outcomes in the group of animals receiving only vincristine were far worse. Thus, the research indicates that betulinic acid may be used as an effective enhancer of the chemotherapeutic effect in malignant melanoma treatment.

The situation of betulin as a pharmacologically and therapeutically useful anti-cancer agent is quite different. Due to the poor solubility in aqueous media, its applications in this field are more limited. Thus far, no publications of clinical trials using anti-cancer potential of betulin have been published [10]. Nonetheless, the disadvantages are counteracted by the high potential of betulin to form derivatives.

\section{CONCLUSIONS}

Betulin, naturally occurring triterpenoid, and one of its derivatives, betulinic acid, show potent anti-cancer activity through triggering the mitochondrial apoptosis pathway in tumour cells. Numerous studies have been conducted to show their significant role in the treatment of solid tumours; some also indicated an influence on haematological malignancies. The usefulness of betulin and betulinic acid as anti-cancer agents may be fully prominent in combination with conventional therapies. The compounds achieved promising results combined with chemotherapeutics or radiotherapy. Betulinic acid is also exploited as a treatment of carcinomas refractory to standard therapies. Regarding their relative selectivity in malignant cells cytotoxicity and ability to spare normal cells, both betulin and betulinic acid seem to be promising candidates for clinical cancer treatment.

\section{REFERENCES}

1.Breitmaier E. Terpenes: Importance, General Structure, and Biosynthesis. 2006.

2. Rabi T, Bishayee A. Terpenoids and breast cancer chemoprevention. Breast Cancer Res Treat. 2009; 115(2): 223-239.

3. Withers ST, Keasling JD. Biosynthesis and engineering of isoprenoid small molecules. Appl Microbiol Biotechnol. 2007; 73(5): 980-990.

4.Liby KT, Yore MM, Sporn MB. Triterpenoids and rexinoids as multifunctional agents for the prevention and treatment of cancer. Nat Rev Cancer. 2007; 7(5): 357-369.

5. Bishayee A, Ahmed S, Brankov N, Perloff M. Triterpenoids as potential agents for the chemoprevention and therapy of breast cancer. Front Biosci. 2011; 16(1): 980.

6. Krajcovicova Z, Vachálková A, Horváthová K, Tóthová D. Pentacyclic Triterpenoic Acids: New Chemoprotective Compounds. Minireview. Neoplasma. 2004; 51: 327-333.

7. Hsu T-I, Chen Y-J, Hung C-Y, Wang Y-C, Lin S-J, Su W-C et al. A novel derivative of betulinic acid, SYK023, suppresses lung cancer growth and malignancy. Oncotarget. 2015; 6(15): 13671-13687.

8. Phillips DR, Rasbery JM, Bartel B, Matsuda SP. Biosynthetic diversity in plant triterpene cyclization. Curr Opin Plant Biol. 2006; 9(3): 305-314.

9. Petronellia A, Pannitterib G, Testaa U. Triterpenoids as new promising anticancer drugs. Anticancer Drugs. 2009; 20(10): 880-892.

10. Laszczyk MN. Pentacyclic triterpenes of the lupane, oleanane and ursane group as tools in cancer therapy. Planta Med. 2009; 75(15): 1549-1560.

11. Alakurtti S, Mäkelä T, Koskimies S, Yli-Kauhaluoma J. Pharmacological properties of the ubiquitous natural product betulin. Eur J Pharm Sci. 2006; 29(1): 1-13.

12. Lin WY, Lin FH, Sadhasivam S, Savitha S. Antioxidant effects of betulin on porcine chondrocyte behavior in gelatin/C6S/C4S/HA modified tricopolymer scaffold. Mater Sci Eng C. 2010; 30(4): 597-604.

13. Şoica CM, Dehelean CA, Peev C, Aluas M, Zupkó I, Kása Jr P, et al. Physico-chemical comparison of betulinic acid, betulin and birch bark extract and in vitro investigation of their cytotoxic effects towards skin epidermoid carcinoma (A431), breast carcinoma (MCF7) and cervix adenocarcinoma (HeLa) cell lines. Nat Prod Res. 2012; 26(10): 968-974.

14. Chintharlapalli S, Papineni S, Ramaiah SK, Safe S. Betulinic acid inhibits prostate cancer growth through inhibition of specificity protein transcription factors. Cancer Res. 2007; 67(6): 2816-2823.

15. Yogeeswari P, Sriram D. Betulinic Acid and Its Derivatives: A Review on their Biological Properties. Curr Med Chem. 2005; 12(6): 657-666.

16. Newman D, Cragg G, Snader K. Natural Products as sources of New Drugs over the Period 1981-2002. J Nat Prod. 2003; 66(7): 1022-1037.

17. Pisha E, Chai H, Lee I-S, Chagwedera TE. Farnsworth NHS, Cordell, GA, et al. Discovery of betulinic acid as a selective inhibitor of human melanoma that functions by induction of apoptosis. Nat Med. 1995; 1(10): 1046-1051.

18. Fulda S. Betulinic acid for cancer treatment and prevention. Int J Mol Sci. 2008; 9(6): 1096-1107.

19. Drag M, Surowiak P, Drag-Zalesińska M, Dietel M, Lage H, Oleksyszyn J. Comparision of the cytotoxic effects of birch bark extract, betulin and betulinic acid towards human gastric carcinoma and pancreatic carcinoma drug-sensitive and drug-resistant cell lines. Molecules. 2009; 14(4): 1639-1651.

20. Thurnher D, Turhani D, Pelzmann M, Wannemacher B, Knerer B, Formanek M, et al. Betulinic acid: A new cytotoxic compound against malignant head and neck cancer cells. Head Neck. 2003; 25(9): 732-740.

21. Wick W, Grimmel C, Wagenknecht B, Dichgans J, Weller M. Betulinic acid- induced apoptosis in glioma cells: a sequential requirement for new protein synthesis, formation of reactive oxygen species, and caspase processing. J Pharmacol Exp Ther. 1999; 289(3): 1306-1312.

22. Gao Y, Ma Q, Ma Y, Ding L, Xu X, Wei D, et al. Betulinic acid induces apoptosis and ultrastructural changes in MDA-MB-231 breast cancer cells. Ultrastruct Pathol. 2017; 00(00): 1-6. 
23. Jae SP, Si HR, Dae KK, Jin GL, Yong YL, Soon SH, et al. Anti-cancer effect of betulin on a human lung cancer cell line: A pharmacoproteomic approach using 2 D SDS PAGE coupled with nano-HPLC tandem mass spectrometry. Planta Med. 2009; 75(2): 127-131.

24. Sun Y, Song C, Viernstein H, Unger F, Liang Z. Apoptosis of human breast cancer cells induced by microencapsulated betulinic acid from sour jujube fruits through the mitochondria transduction pathway. Food Chem. 2013; 138(2-3): 1998-2007.

25. Schmidt ML, Kuzmanoff KL, Ling-Indeck L, Pezzuto JM. Betulinic acid induces apoptosis in human neuroblastoma cell lines. Eur J Cancer. 1997; 33(12): 2007-2010.

26. Chintharlapalli S, Papineni S, Lei P, Pathi S, Safe S. Betulinic acid inhibits colon cancer cell and tumor growth and induces proteasomedependent and -independent downregulation of specificity proteins (Sp) transcription factors. BMC Cancer. 2011; 11(1): 371.

27.Zhang X, Hu J, Chen Y. Betulinic acid and the pharmacological effects of tumor suppression (Review). Mol Med Rep. 2016; 14(5): 4489-4495.

28. Ehrhardt H, Fulda S, Führer M, Debatin KM, Jeremias I. Betulinic acidinduced apoptosis in leukemia cells. Leukemia. 2004; 18(8): 1406-1412.

29. Rzeski W, Stepulak A, Szymański M, Juszczak M, Grabarska A, Sifringer M, et al. Betulin Elicits Anti-Cancer Effects in Tumour Primary Cultures and Cell Lines in Vitro. Basic Clin Pharmacol Toxicol. 2009; 105(6): 425-432.

30. Rzeski W, Stepulak A, Szymañski M, Sifringer M, Kaczor J, Wejksza K, et al. Betulinic acid decreases expression of bcl-2 and cyclin D1, inhibits proliferation, migration and induces apoptosis in cancer cells. Naunyn Schmiedebergs Arch Pharmacol. 2006; 374(1): 11-20.

31. Fulda S, Debatin K. Sensitization for Anticancer Drug-Induced Apoptosis by Betulinic Acid. Neoplasia. 2005; 7(2): 162-170.

32. Sawada N, Kataoka K, Kondo K, Arimochi H, Fujino H, Takahashi Y, et al. Betulinic acid augments the inhibitory effects of vincristine on growth and lung metastasis of B16F10 melanoma cells in mice. Br J Cancer. 2004; 90(8): 1672-1678.

33. Selzer E, Pimentel E, Wacheck V, Schlegel W, Pehamberger H, Jansen B, et al. Effects of Betulinic Acid Alone and in Combination with Irradiation in Human Melanoma Cells. J Invest Dermatol. 2000; vol 114: 935-940.

34. Zuco V, Supino R, Righetti SC, Unger F, Liang Z. Selective cytotoxicity of betulinic acid on tumor cell lines, but not on normal cells. Cancer Lett. 2002; 175(1): 17-25.

35.Zeng A-Q, Yu Y, Yao Y-Q, Yang F-F, Liao M, Song L-J, et al. Betulinic acid impairs metastasis and reduces immunosuppressive cells in breast cancer models. Oncotarget. 2018; 9(3): 3794-3804.

36. Shin YG, Cho KH, Chung SM, Graham J, Das Gupta TK, Pezzuto JM. Determination of betulinic acid in mouse blood, tumor and tissue homogenates by liquid chromatography-electrospray mass spectrometry. J Chromatogr B Biomed Sci Appl. 1999; 732: 331-336.

37. Jäger S, Laszczyk MN, Scheffler A. A Preliminary Pharmacokinetic Study of Betulin, the Main Pentacyclic Triterpene from Extract of Outer Bark of Birch (Betulae alba cortex). 2008: 3224-3235. 